\title{
Frequency of Congenital Fetal Anomalies and Associated Risk Factors Among Patients of the Radiology Department of Frontier Medical and Dental College Abbottabad
}

\author{
Nosheen Rehan, Rehan Farooqui, Talha Ahmad Farooqui \\ Department of Radiology, Frontier Medical College, Abbottabad
}

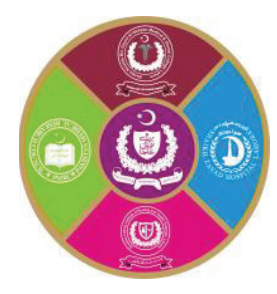

\begin{abstract}
Introduction: Radiology Department has played a key role in the diagnosis of varied congenital anomalies. Aims \& Objectives: The aim of the study is to assess these anomalies amongst pregnant females presenting to the Radiology Department of Frontier Medical and Dental College Abbottabad for antenatal obstetric ultrasound and to evaluate associated risk factors of congenital anomalies among them. Place and duration of study: It is an observational study conducted at the Radiology Department of Frontier Medical and Dental College for 2 years from September 2015 to September 2017. Material \& Methods: Twelve thousand four hundred patients came for antenatal ultrasound scan to determine frequency of congenital anomalies and its types. The cases with congenital anomalies were analyzed for types and associated risk factors. Results: The frequency of congenital anomalies was found to be twelve per one thousand in the study population. Neural Tube Defects were found to be the most common type of congenital anomalies and anencephaly was the most common type among neural tube defects. Other common congenital anomalies were Hydrops fetalis followed by bladder outlet obstruction. A high association of folic acid deficiency was found with neural tube defects. Also, patients with poor socioeconomic status, consanguineous marriage, and iron deficiency anemia were found to have a higher association with congenital anomalies. Conclusion: The frequency of congenital anomalies was found to be twelve per one thousand in study population. Neural Tube Defect was found to be the most common type of congenital anomaly. Majority of cases were associated with some risk factor.
\end{abstract}

Key words: Congenital anomalies, Neural tube defects, Anencephaly, Antenatal, Ultrasound.

\section{INTRODUCTION}

$\mathrm{C}$ ongenital anomalies are one of the major cause of neonatal morbidity and mortality. ${ }^{1}$ A congenital anomaly can be defined as fetal structural or functional anomaly that occurs during intrauterine life and can be detected antenatally, perinatally or later in life. An estimated 303,000 newborns die within 4 weeks of age due to congenital anomalies. ${ }^{2}$ Congenital anomalies can contribute to long-term disability which may have a significant impact on individual, families, health care systems and societies. ${ }^{3}$ Various risk factors have been associated with these anomalies including infections, enviourmental and genetic factors. In some cases, either there is no known cause or there is multifactorial etiology. Folic acid deficiency and teratogenic drugs are other risk factors in this regard. ${ }^{4}$

Early pregnancy (first trimester) is vital for organogenesis and any insult during this time will lead to damage to the organs leading to congenital anomalies. ${ }^{5}$ It is known that folic acid helps in the prevention of neural tube defects if taken before conception. ${ }^{6}$ The main diagnostic tool for the detection of fetal congenital anomalies is ultrasound. ${ }^{7}$ It allows examination of internal and external anatomy of fetus and is helpful in detection of not only major congenital anomalies but also chromosomal and genetic disorders that present with various malformations. ${ }^{8}$ The ultrasound scan done at 18-23 weeks of gestation is highly important in this regard and is called anomaly scan. ${ }^{9}$ Commonly seen anomalies are neural tube defects. Amongst them anencephaly and spina bifida are more common. ${ }^{10}$ Other commonly detected congenital anomalies on ultrasound are hydrops fetalis, skeletal dysplasias and renal anomalies. ${ }^{11}$

This study is designed to find out frequency and risk factors for occurrence of congenital fetal anomalies in patients of Frontier Medical College Abbottabad, and will provide new data for health care facilities to take steps for prevention. 


\section{MATERIAL AND METHODS}

The study was conducted in the Department of Radiology of Frontier Medical and Dental College Abbottabad. Frontier Medical College is a secondary care teaching hospital in private sector and is equipped with state of art diagnostic and therapeutic facilities. It caters a large area from Abbottabad to Mansehra, including many small habitations in between these two cities.

About 11,000 routine ultrasounds are done every year, out of which about 7,500 are obstetric ultrasounds. The study population comprised of pregnant females coming to hospital for antenatal obstetric ultrasound. They were either requested from Obstetrics and Gynecology department of FMC, or referred to our department from other hospitals and clinics of the area. The patients were selected by convenient sampling method.

A consultant radiologist performed all antenatal obstetric ultrasound using Esaote MyLab 20 plus Ultrasound Machine with $3.5 \mathrm{MHz}$ probe.

Verbal informed consent was obtained before performing ultrasound. Patients were scanned for frequency and type of congenital fetal anomalies. Detailed fetal anatomical survey was done at the time of examination.

The cases with congenital anomalies were analyzed filling a predesigned Proforma. Demographic variables like fetal gender, gestational age etc, types of congenital anomalies and associated risk factors were also recorded in the proforma. Findings were confirmed clinically in case of termination or stillbirth and by repeating ultrasound scan after birth in cases of live birth.

\section{Inclusion Criteria}

All pregnant patients coming to Radiology Department of FMC from September 2015 till September 2017 with request for antenatal obstetric ultrasound either from Gynecological Obstetrics Department of FMC or referred from outside hospitals and clinics.

\section{Exclusion Criteria}

Patients of gestational age less than 11 weeks.

Patients with missed abortion.

Patients with intrauterine death of fetus.

Statistical analysis:

Results were tabulated and data entered and analyzed by SPSS version 10. Research protocol was approved by Research Ethics Committee of FMC.

\section{RESULTS}

Out of total 12,400 patients, 570 had congenital anomaly. Regarding maternal age, out of 570 cases with congenital anomalies, in 237 cases, maternal age was 17-20 years, in 188 cases maternal age was 20-35 years. Regarding parity, 379 cases with anomalies were seen in multigravida mothers. There was history of consanguinity in 299 cases with congenital anomalies. A total of 292 cases with congenital anomalies belonged to poor socioeconomic status. In 270 cases with congenital anomalies, maternal hemoglobin was less than $10 \mathrm{gm} / \mathrm{dl}$.

In 438 cases of congenital anomalies, mother did not use folic acid and 292 cases with congenital anomalies were detected in $3^{\text {rd }}$ trimester.

Out of positive cases, 296 fetuses were of male gender and 274 cases were of female gender.

Neural tube defects were the commonest seen anomalies (210/570) and among them commonest were anencephaly (57) followed by spina bifida (48) and myelomeningocele (33). 39 cases of skeletal dysplasia, 25 of gastroschisis, 23 cases each of omphalocele and short femur, 31 of bladder outlet obstruction, 15 of multicystic dysplastic kidneys, 38 of hydrops fetalis, 29 of congenital cardiac defect and 17 cases of cleft lip/palate were also seen.

\begin{tabular}{|c|c|c|}
\hline Parental Risk Factor & $\begin{array}{l}\text { Cong. } \\
\text { Anomaly +ive }\end{array}$ & $\begin{array}{l}\text { Cong. } \\
\text { Anomaly -ive }\end{array}$ \\
\hline 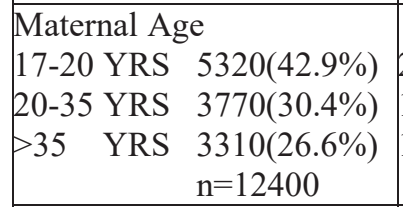 & $\begin{array}{l}237(1.9 \%) \\
188(1.5 \%) \\
145(1.1 \%)\end{array}$ & $\begin{array}{l}5083(40.9 \%) \\
3528(28.8 \%) \\
3165(25.5 \%)\end{array}$ \\
\hline $\begin{array}{ll}\text { Parity } & \\
\text { PG } & 3520(28.3 \%) \\
\text { MG } & 8880(71.6 \%)\end{array}$ & $\begin{array}{l}191(1.5 \%) \\
379(3.05 \%)\end{array}$ & $\begin{array}{l}3329(26.8 \%) \\
8501(68.5 \%)\end{array}$ \\
\hline $\begin{array}{l}\text { H/O Consanguinity } \\
\text { Absent } \quad 5311(42.8 \%) \\
\text { Present } \quad 7098(57.1 \%)\end{array}$ & $\begin{array}{l}271(2.1 \%) \\
299(2.4 \%)\end{array}$ & $\begin{array}{l}5040(40.6 \%) \\
6790(54.75 \%)\end{array}$ \\
\hline \begin{tabular}{|ll|}
\multicolumn{3}{|c}{ Monthly Income of Family } \\
20,000 & $4168(33.6 \%)$ \\
$20-30,000$ & $6214(50.1 \%)$ \\
30,000 & $2018(16.2 \%)$ \\
\end{tabular} & $\begin{array}{l}292(2.3 \%) \\
223(1.79 \%) \\
145(1.69 \%)\end{array}$ & $\begin{array}{l}3966(31.98 \%) \\
5991(48.31 \%) \\
1873(15.1 \%) \\
\end{array}$ \\
\hline $\begin{array}{|ll|}\text { Antenatal Visits } \\
<3 & 8010(64.5 \%) \\
3 & 390(35.4 \%) \\
\end{array}$ & $\begin{array}{l}315(2.5 \%) \\
255(2.05 \%)\end{array}$ & $\begin{array}{l}7695(62.0 \%) \\
4135(33.3 \%) \\
\end{array}$ \\
\hline 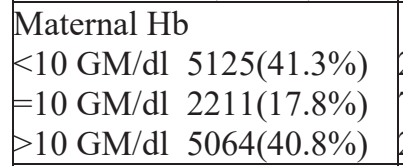 & $\begin{array}{l}270(2.1 \%) \\
71(0.57 \%) \\
229(1.8 \%)\end{array}$ & $\begin{array}{l}4835(39.1 \%) \\
2140(17.2 \%) \\
4835(38.9 \%) \\
\end{array}$ \\
\hline \begin{tabular}{|ll} 
Maternal Use of Folic Acid \\
Yes & $3170(25.1 \%)$ \\
No & $9230(74.4 \%)$
\end{tabular} & $\begin{array}{l}132(1.06 \%) \\
438(3.5 \%)\end{array}$ & $\begin{array}{l}3036(24.4 \%) \\
8792(70.9 \%)\end{array}$ \\
\hline \begin{tabular}{|l} 
Gestational Age \\
$1^{\text {st }}$ Trimester $2150(17.3 \%)$ \\
$2^{\text {nd }}$ Trimester $3760(30.3 \%)$ \\
$3^{\text {rd }}$ Trimester $6490(52.3 \%)$
\end{tabular} & $\begin{array}{l}113(0.91 \%) \\
165(1.33 \%) \\
292(2.3 \%)\end{array}$ & $\begin{array}{l}2037(16.4 \%) \\
3595(28.9 \%) \\
6198(47.9 \%) \\
\end{array}$ \\
\hline
\end{tabular}

Table-1: Parental Demographic Characteristics 


\begin{tabular}{|l|l|l|}
\hline Fetal Factors & $\begin{array}{l}\text { Congenital } \\
\text { Anomaly +ive }\end{array}$ & $\begin{array}{l}\text { Congenital } \\
\text { Anomaly -ive }\end{array}$ \\
\hline $\begin{array}{l}\text { Gender } \\
\text { Male } 5600\end{array}$ & $296(5.2 \%)$ & $5304(94.7 \%)$ \\
Female 6800 & $274(4.0 \%)$ & $6526(95.9 \%)$ \\
n=12400 & & \\
\hline $\begin{array}{l}\text { Type of Pregnancy } \\
\text { Single 10300 }\end{array}$ & $471(4.57 \%)$ & $9829(95.4 \%)$ \\
Twin 2100 & $91(4.3 \%)$ & $2009(95.6 \%)$ \\
\hline H/O Birth Defects in & & \\
Family & & \\
Among Total Patients & & \\
YES 3200(26.6\%) & $213(6.6 \%)$ & $2987(93.3 \%)$ \\
NO 9200(76.6\%) & $357(3.8 \%)$ & $8843(96.1 \%)$ \\
\hline
\end{tabular}

Table-2: Fetal Demographic Characteristics

\begin{tabular}{|l|l|l|l|}
\hline System & Type of Anomaly & $\begin{array}{l}\text { No. of } \\
\text { Patients }\end{array}$ & \%age \\
\hline CNS & Anencephaly & 57 & $10 \%$ \\
& Spina Bifida & 48 & $8.4 \%$ \\
& Mylomeningocele & 33 & $5.7 \%$ \\
& Arnold Chiari & 27 & $4.7 \%$ \\
& Encephalocele & 13 & $2.2 \%$ \\
& Hydrocephalus & 23 & $4.03 \%$ \\
& Dandy Walker & 4 & $0.7 \%$ \\
& Holoprosencephaly & 5 & $0.87 \%$ \\
\hline Total & & $210 / 570$ & $36.8 \%$ \\
\hline Musculo- & Skeletal Dysplasia & 39 & $6.8 \%$ \\
Skeletal & Gastroschisis & 25 & $4.3 \%$ \\
& Omphalocele & 23 & $4.0 \%$ \\
& Short Femur & 23 & $4.0 \%$ \\
& Polydactyly & 20 & $3.5 \%$ \\
\hline Total & & $130 / 570$ & 22.85 \\
\hline Renal & Bladder Outlet Obstruction & 31 & 5.45 \\
& Multicystic Dysplastic Kidneys 15 & $2.6 \%$ \\
& Unilateral Renal Agenesis & 7 & $1.2 \%$ \\
& Bilateral Renal Agenesis & 2 & $0.35 \%$ \\
& PUj Obstruction & 22 & $3.85 \%$ \\
\hline Total & & $77 / 570$ & $13.5 \%$ \\
\hline Miscella- & Cong.Cardiac Defects & 29 & $5.08 \%$ \\
neous & Cong. Diaphragmatic Hernia & 16 & $2.8 \%$ \\
& Hydrops Fetalis & 38 & $6.6 \%$ \\
& Cystic Hygroma & 18 & $3.1 \%$ \\
& Cleft Lip/Palate & 17 & $2.98 \%$ \\
& Duodenal Atresia & 14 & $2.4 \%$ \\
& Intestinal Obstruction & 21 & $3.6 \%$ \\
\hline Total & & $153 / 570$ & $26.8 \%$ \\
N=570 & & & \\
\hline
\end{tabular}

Table-3: Distribution of Congenital Anomalies in Each System

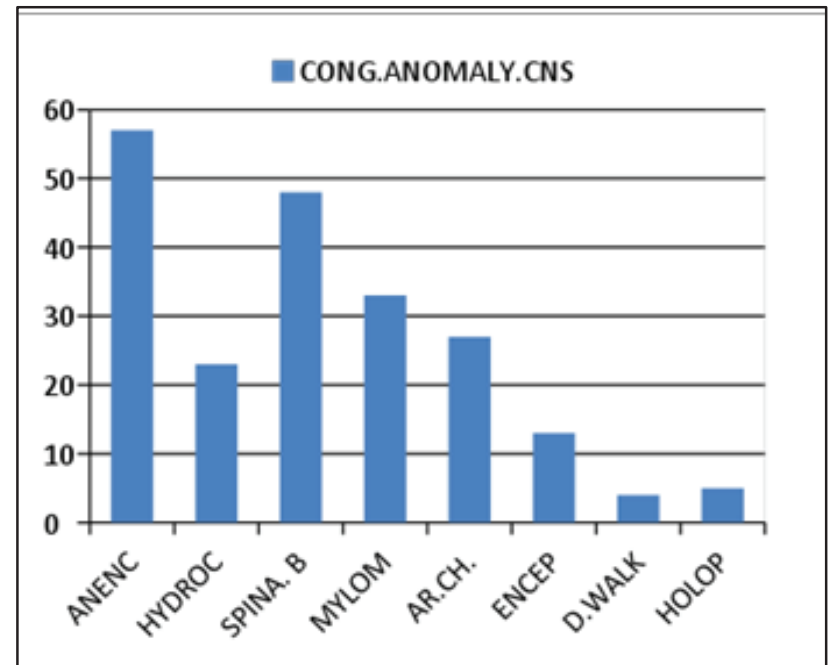

Fig-1: Graph of Congenital (Cong.) anomalies of CNS

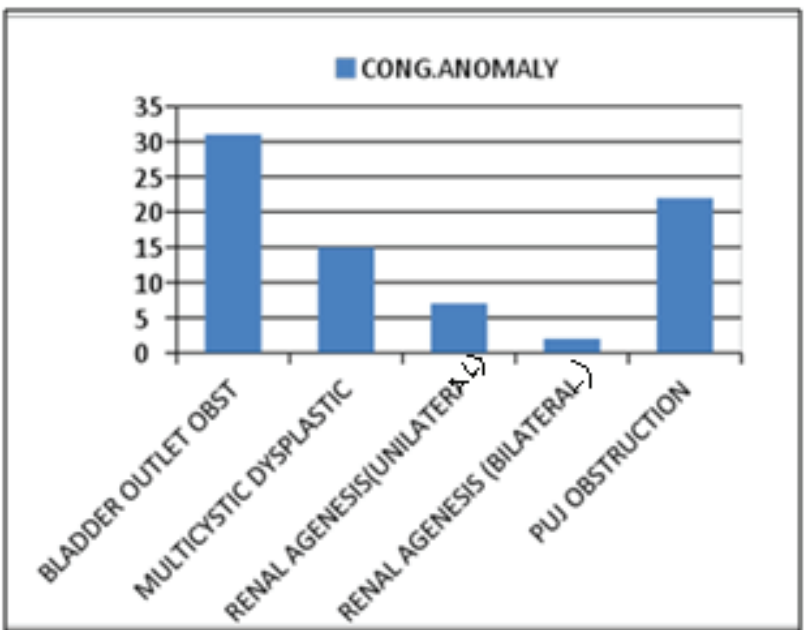

Fig-2: Congenital (Cong.) anomalies of Renal System

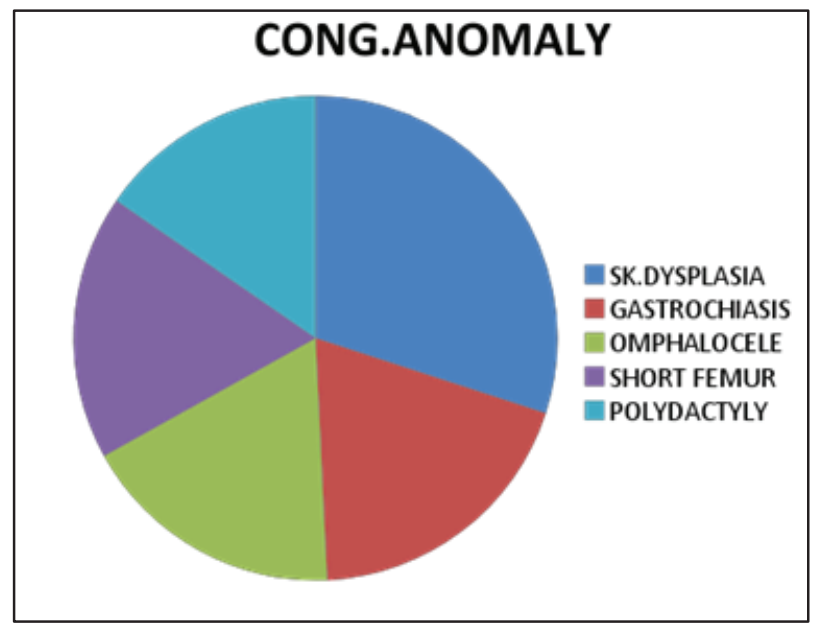

Fig-3: Pie chart of Congenital (Cong.) anomalies of Musculoskeletal system 


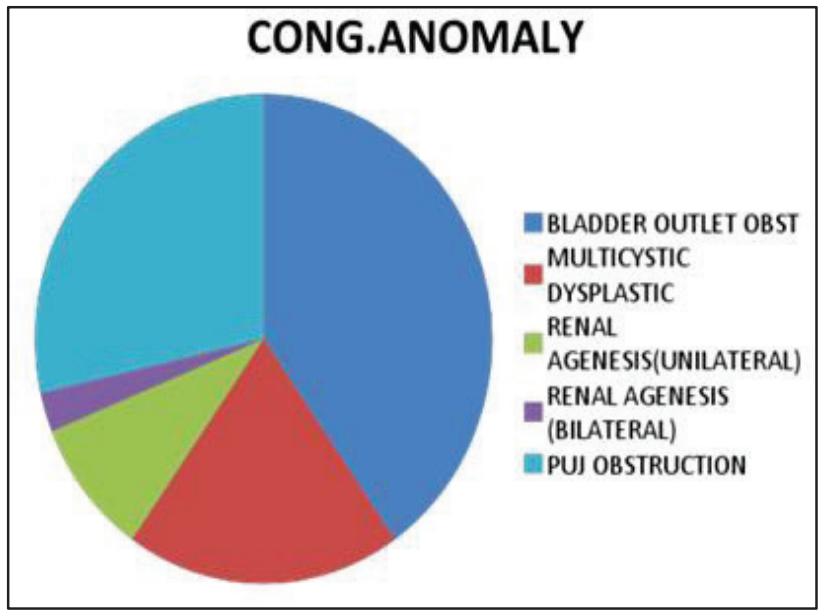

Fig-4: Pie chart of Congenital (Cong.) anomalies of Renal system

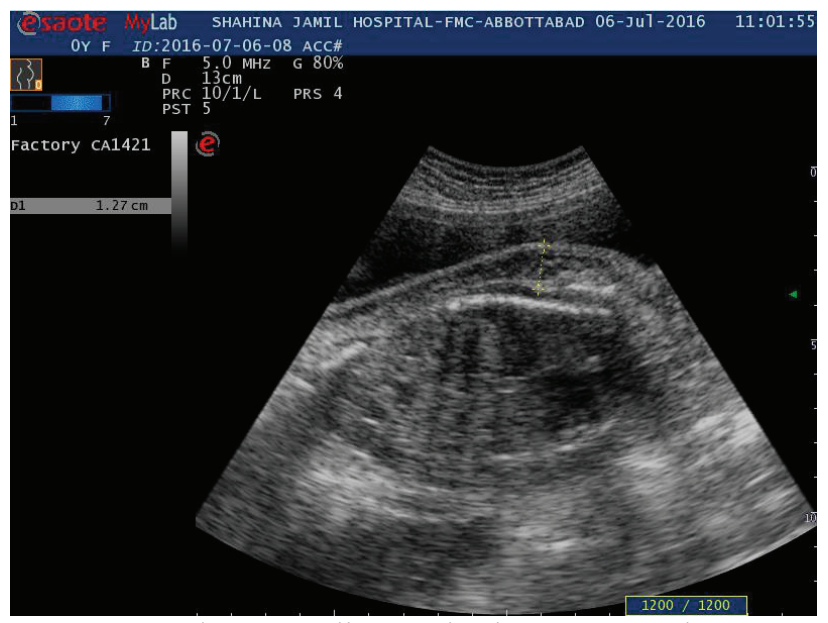

Image-1: Hydrops Fetalis, Fetal subcutaneous edema

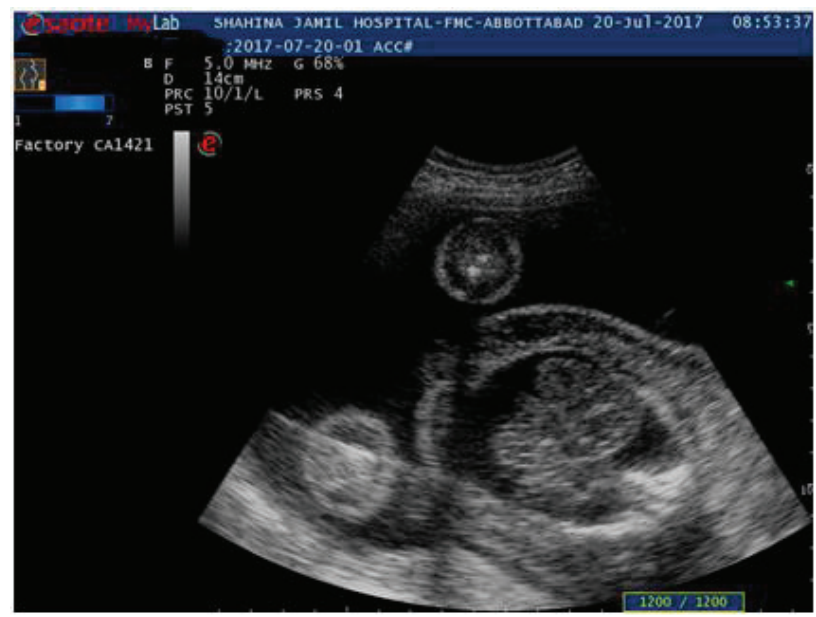

Image-2: Hydrops Fetalis, Fetal Ascites

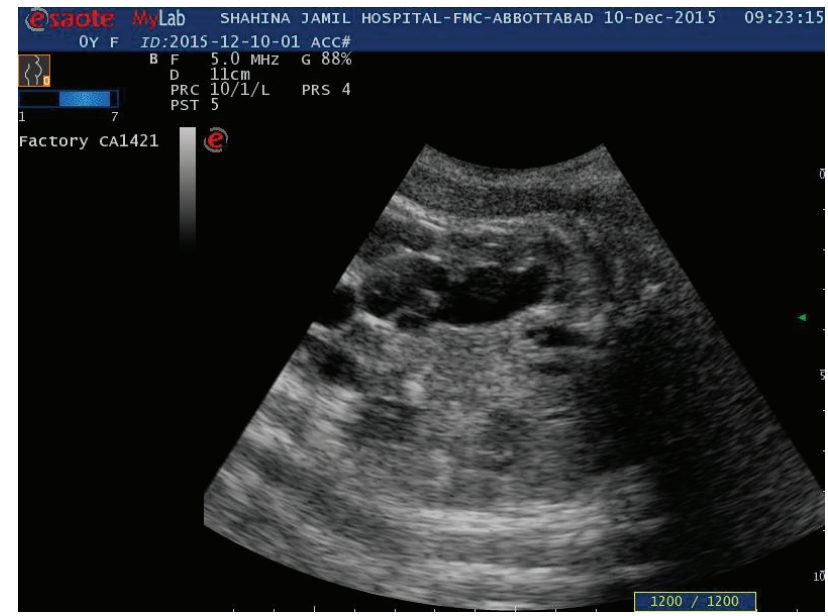

Image-3: Fetal Renal Hydronephrosis

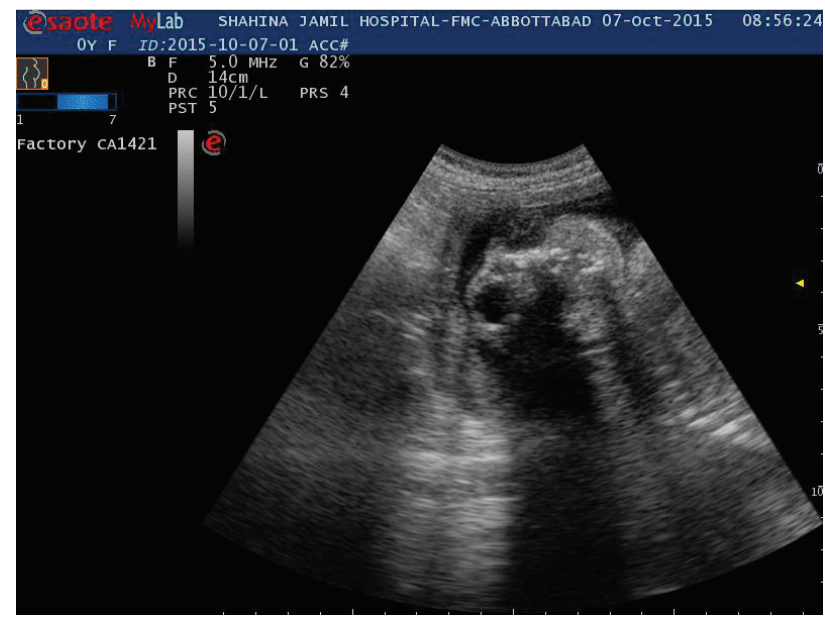

Image-4: Anencephaly

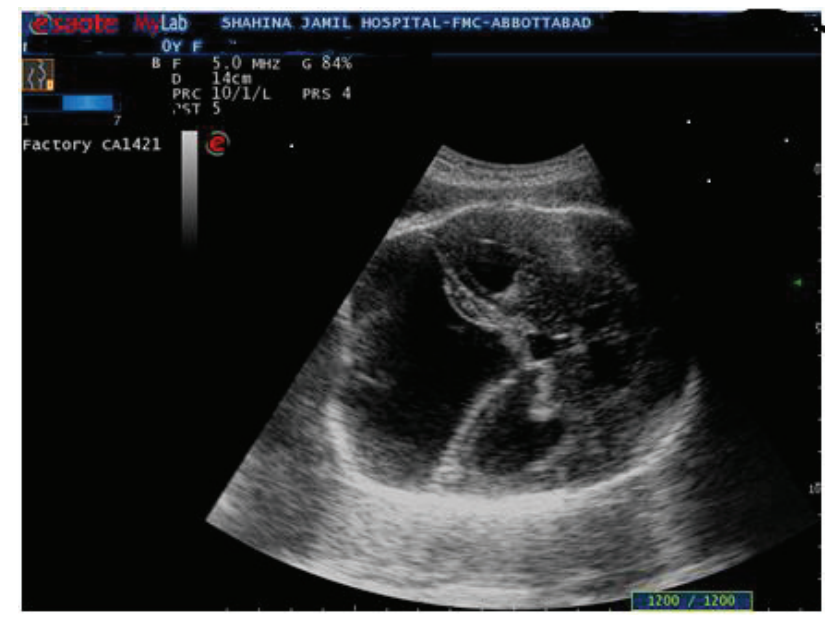

Image-5: Dandy Walker malformation 


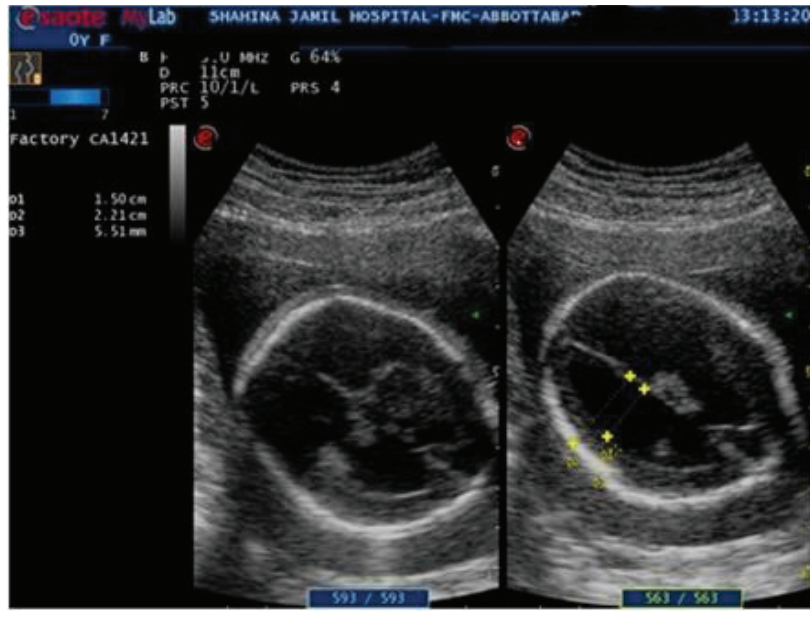

Image-6: Hydrocephalus

\section{DISCUSSION}

Our population based study involved 12,400 pregnant females coming to Department of Radiology of Frontier Medical College Abbottabad, Pakistan, for antenatal obstetric ultrasound. Out of these 12,400 patients, 570 were found to have some fetal congenital anomaly on antenatal obstetric ultrasound, the incidence being $12 / 1000$, which is significantly high as compared to the incidence of congenital anomalies in developed countries.

Overall, the worldwide frequency of congenital anomalies is found to be $1 / 500$ live births. ${ }^{12}$ But this incidence varies in different countries because its causes are multifactorial including genetic, infectious, nutritional and environmental factors. The incidence is significantly lower in developed countries like United States, Canada and Australia etc and higher in developing countries like Pakistan, India and Bangladesh etc. ${ }^{13}$ The incidence in our study is comparable to other studies from India and Saudi Arabia. ${ }^{14,15}$

In present study, majority of our patients belonged to low socioeconomic group with monthly income less than 30,000 Pakistani Rupees. Similar studies Tella Sunitha et al showed higher incidence of congenital anomalies in low socioeconomic group. ${ }^{16}$ Low income may be indirect determinant of congenital anomalies with high frequency among resource constrained familes and countries. It is estimated that about $94 \%$ of severe congenital anomalies occur in low and middle income households, which causes risk due to a possible lack of access to sufficient nutritious food by pregnant women, poor access to health care and screening facilities and increased exposure to infections like Rubella and Syphilis etc. ${ }^{17}$

Amongst 12,400 patients, 5064 patients were found to have hemoglobin less than $10 \mathrm{~g} / \mathrm{dl}$. And 9230 were found not to have taken folic acid supplements in periconceptional period and early pregnancy. The results are comparable to studies done by Rasheed $\mathrm{N}$ et al and Josef Gaber et al. revealing the fact that low folic acid level and anemia may lead to increased incidence of congenital anomalies especially neural tube defects. ${ }^{18,19}$

CNS anomalies including Neural tube defects were found to be the most common congenital anomaly detected antenatally in our study (36.8\%). Similar studies by Robin B et al. ${ }^{20}$ and G Barry Borman et al. ${ }^{21}$ showed neural tube defects to be the most common antenatally diagnosed congenital anomalies. Most of our patients were not taking folic acid supplements and were anemic which may have led to high incidence of neural tube defects in our study.

Folic acid administration to pregnant women drastically reduced birth prevalence of neural tube defects in US, Canada, Chile and Costa Rica. These countries fortified flour between 1998 to 2000 which resulted in $23-78 \%$ reduction in neural tube defects rate. ${ }^{22}$

WHO is also working with partners to provide required technical expertise for surveillance of neural tube defects, for monitoring fortification of staple foods with folic acid and for improving laboratory capacity for assessing risks for folic acid preventable congenital anomalies.

Fewer than 1 in 3 women in the study area consume the amount of folic acid recommended by United States Public Health Services. Therefore, we recommend urgent and effective campaign to close this prevention gap and policies be made in collaboration with WHO and US CDC to implement and follow global policies for food fortification with folic acid at country level.

Many of our patients came for antenatal screening ultrasound in late second or in third trimester as patients were unaware of significance of early antenatal screening. Most of the countries have an official policy for routine ultrasound anomaly scan at 18-22 weeks of gestation. Unfortunately, in our country there is no such policy. According to National collaborating center for women's and children's health 2008 (NICE) Guidance, pregnant women should be offered an ultrasound scan to screen for structural anomalies, ideally between $8^{\text {th }}$ week to $20^{\text {th }}$ week of gestation. ${ }^{23}$ Screening later than $20^{\text {th }}$ week of gestation may delay the diagnosis of abnormality to the point where termination of an affected fetus becomes problematic and may involve additional procedures such as feticide. ${ }^{24}$

Maternal age is found to be an important parameter in relation to congenital anomalies as incidence was 
found to be more in younger patients. Similar study by Hollier et al showed increased incidence of congenital anomalies in younger patients. ${ }^{25}$

Consanguineous marriages are very common in our country especially in the areas of study. $57.1 \%$ of our patients had history of consanguineous marriage, which may have led to higher incidence of congenital anomalies in the area of study. Similar studies by Barbour $\mathrm{B}$ et al and Tayebi $\mathrm{N}$ et al showed consanguineous marriages as a cause of congenital anomalies. ${ }^{26,27}$

On the whole malnutrition, poverty, younger age, lack of education and awareness and lack of access to health care facilities are all contributory factors for high prevalence of congenital fetal anomalies in the area of our study. It indicates health care providers and health policy makers need to make strong preventive measures to reduce the incidence of congenital fetal anomalies in the area, such as:

1- Increasing awareness about maternal care during pregnancy and educational programs on congenital anomalies and awareness regarding the consequences of consanguineous marriages and younger age pregnancies need to be highlighted in order to reduce the incidence of congenital anomalies in the area.

2- Ensuring pregnant women have a healthy diet including wide variety of fruits and vegetables and maintain a healthy weight.

3- Ensuring an adequate dietary intake of vitamins and minerals especially iron and folic acid by pregnant women.

4-Vaccination especially against Rubella for women 5- Increasing and strengthening education of health staff and others involved in promoting the prevention of congenital anomalies.

\section{CONCLUSION}

The frequency of congenital fetal anomalies in the area of study is significantly higher as compared to developed countries.

Poor socioeconomic status, malnutrition, iron deficiency anemia, folic acid deficiency, younger age of pregnant women, tradition of consanguineous marriages and lack of awareness regarding early anomaly scan are all associated factors which may have led to high incidence of congenital anomalies in the area of study.

The study provides new data for health care facilities, however, additional larger community based studies are needed to assess the magnitude of problem in the area and to find out causative factors and additional steps for prevention.

\section{REFERENCES}

1. S Sarkar, C Patra, M Kumar et al. Prevalence of congenital anomalies I neonates and associated risk factors in a tertiary care hospital I eastern India. J CLIN NEONATAL. 2013 JUL-SEP; 2(3):131-134. WHO, 63 world health assembly A 63/10 1 April 2010.

2. www.who.int/mediacentre/fact sheets/fs $370 /$ ens

3. A Akrati, SP Rathod, SV Patel, SM Patel. A study of congenital anomalies in newborn. NJIRM,1(2010), p.1

4. M. Sheeba, S. Sushmita, K. Harprat, G Monika. Surveillance of congenital malformations and their possible risk factors in a teaching hospital in Punjab. Ind $\mathrm{j}$ Reprod contracept obstet gynecol, 3 (1) (2014), pp 162-167.

5. World Health Organization. Report on regional consultation towards the development of a strategy for optimizing fetal growth and development. Cairo, WHO regional office for the Eastern Mediterranean 2005.

6. Centers for disease control and prevention (1991) Use of folic acid for prevention of spina bifida and other neural tube defects: 1983-1991. MMWR 40: 513-16.

7. World Health Organization. TRAINING IN DIAGNOSTIC ULTRASOUND: essentials, practice and standards. Geneva, WHO (WHO Technical report series No.875), 1998.

8. Goldberg, JD. Routine screening for fetal anomalies: expectations. Obstet Gynecol Clin North Am 2004; 31:35-50.

9. Gracia J, Bricker L, Henderson J, Martin MA, Women's view of pregnancy ultrasound: a systematic review. Birth 2002; 29:225-50

10. Centers for disease control and prevention. Surveillance for anencephaly and spina bifida and impact on prenatal diagnosis. United states, 1985-1994. MMWR. 1996; 44(ss-4) 1-13

11. Taksande A, Vilhekar K, Chaturvedi P, Jain M. Congenital malformations at birth in central India: A rural medical college hospital based data. Indian J Hum Genet. 2010; 16: 159-63.

12. World health organization. Section on congenital anomalies (cited on $2012 \mathrm{t}$ )

13. Kurinczuk JJ, HOLLWELL J, BROCKIEH URST P, GRAY R. Inequalities in infant mortality project briefing paper 1. Infant mortality: overview and context. Oxford: National perinatal Epidemiology unit, University of Oxford. 2009.

14. Taksande A, Vilhekar K, Chaturvedi P, Jain M. Congenital malformations at birth in central 
India: A rural medical college hospital based data. Indian J Hum Genet. 2010; 16: 159-63.

15. Mir NA et al. easily identifiable congenital malformations in children: survey of incidence and pattern in 32332 live born neonates. Annals of Saudi Medicine 1992;12:366-71

16. Tella Sunitha, Kattekola Rebekah Prasoona, Tiruvatturu Muni Kumari. Risk factors for congenital anomalies in high risk pregnant women: A large study from South INDIA. Egyptian journal of Medical Human Genetics 2016.

17. M Florentina, Z Antke, LC Phillipo, RK Benson; Pattern and factors associated with congenital anomalies among young infants admitted at Bugando medical center Mwanza, Tanzania. BMS Res notes, 7(2014), p.195.

18. Rasheed N, Ahmad M, Yar HM. Neural tube defects: prevalence in population of Rahim Yar Khan. Professional Med J June 2009: 16 (2) 270-273.

19. Josef Gabor Joo, Arture Beke, Csaba Papp et al. Neural tube defects in sample of genetic counseling. Wiley Inter Science 2007: 27:912921.

20. Robin B. kalish, Jane SZ, Frank A: fetal cranio spinal and facial abnormalities. High risk pregnancy management options. 2006; 18:369396

21. G. Berry Borman, Allahm H. smith, Jkeir Howard. Risk factors in the prevalence of anencephalous and spina bifida in New Zealand. Wiley inter science 2005; 33:221-230.

22. Lopez-Camelo JS, Orioli IM, da Graca Dutra M et al. Reduction of birth prevalence rates of neural tube defects after folic acid fortification in Chile. Am J Med Genet A 2005; 135:120.

23. Antenatal care: Routine care for the healthy pregnant women. NICE clinical guidelines, No.62. National collaborating center for women's and children's health (UK). London: RCOG press; 2008 Mar.

24. Brich MR, Grayson N, Sulivan EA. AIHW Cat. Birth Anomalies Series No.1. Sydney: AIHW National perinatal statistics unit; 2004. Recommendations for development of new Austeralian birth anomalies system: A review of the congenital malformations and birth defect data collection

25. Hollia LM et al. Cunninghum FG. Maternal age and malformations in singleton birth. Obstetrics and gynecology 2000; 96:701-6.

26. Barbour B et al. Consanguinity in Labenon: prevalence, distribution and determinants. Journal of biosocial science 2009; 41:505-17.
27. Tayebi $\mathrm{N}$ et al. The prevalence of congenital anomalies in consanguineous marriages. Oman medical journal 2010; 25:37-40.

\section{The Authors:}

Dr. Nosheen Rehan,

Assistant Professor,

Department of Radiology,

Frontier Medical College, Abbottabad.

Dr. Rehan Farooqui,

Assistant Professor,

Department of Radiology,

Frontier Medical College, Abbottabad.

Talha Ahmad Farooqui,

Intern,

Frontier Medical College Abbottabad

\section{Corresponding Author:}

Dr. Nosheen Rehan,

Assistant Professor,

Department of Radiology,

Frontier Medical College, Abbottabad.

E-mail: nosheenrehan25@yahoo.com 